\title{
Viabilidade e interações do plantio consorciado de pinhão-manso e girassol
}

Ricardo Coeli Simões Coelho ${ }^{1}$

Lee Tseng Sheng Gerald²

\section{Resumo}

Com o recente advento do biodiesel no Brasil, houve um aumento significativo no número de pesquisas com as oleaginosas potenciais como matéria-prima, destacando-se o Pinhão-Manso (Jatropha curcas L.), tanto devido às excelentes características técnicas do óleo, bem como à rusticidade e produtividade da planta. Contudo, como a produção econômica do pinhão-manso inicia-se a partir do terceiro ano, há necessidade de estudar o plantio em sistema de consórcio. 0 objetivo deste trabalho foi avaliar as interações e a viabilidade técnica e econômica do consórcio de pinhão-manso e girassol (Helianthus annuus L.). Também foi objeto de estudo a produtividade da cultura do girassol e o desenvolvimento das plantas de pinhão-manso sob a influência de sua semeadura nos lados oeste e leste das filas de cultivo. Possíveis efeitos alelopáticos entre as culturas foram avaliados. 0 projeto foi implantado no campus da UFSCar, em Araras, São Paulo. As mudas de pinhão-manso foram plantadas em maio de 1998, no espaçamento de 2 metros entre as plantas e de 4 metros entre as linhas de plantio. A semeadura do girassol, variedade larama, foi realizada em novembro de 2008 , com quatro linhas de plantio, espaçadas em cinquenta centímetros, estimando-se 50.000 plantas por hectare. Adotou-se o delineamento de parcelas subdivididas, com quatro repetições e quatro combinações de consórcios, sendo, T1: plantio de girassol em ambos os lados da linha de plantio de pinhão-manso; T2: plantio de girassol a oeste da linha de pinhão-manso, o lado leste foi reservado para germinação de plantas espontâneas; T3: plantio de girassol a leste da linha de pinhão-manso, o lado oeste foi reservado para germinação de plantas espontâneas; T4: ambos os lados da linha de pinhão manso foram reservados para a germinação de plantas espontâneas. Foi concluído que não houve influência no desenvolvimento do pinhão-manso em plantio consorciado com girassol e que a produção do girassol também não foi influenciada pelo pinhão-manso. Observou-se também uma inibição de plantas espontâneas nas áreas com girassol. A alternativa deste consórcio demonstra ser uma boa opção para o programa nacional de biodiesel.

Palavras-chave: Agroecologia. Alelopatia. Agricultura familiar.

\section{Introdução}

Inúmeros sistemas englobam técnicas que fazem uma adequação dos meios produtivos, priorizando a manutenção dos processos ecológicos. Uma visão agroecológica incorporada ao sistema produtivo agrega valores positivos em sua sustentabilidade, sobretudo através do sistema de produ-

1 Universidade Federal de São Carlos, Centro de Ciências Agrárias - Araras - SP, Programa de Pós-Graduação em Agroecologia e Desenvolvimento Rural, Aluno Mestrando, coelhocitrus@yahoo.com.br. (19) 97858608. Rua 4, número 555, apartamento 11. Rio Claro - São Paulo, CEP 13500-030.

2 Universidade Federal de São Carlos, Centro de Ciências Agrárias - Araras - SP, Programa de Pós-Graduação em Agroecologia e Desenvolvimento Rural, Professor Orientador, leetseng@cca.ufscar.br. (19) 35432582. Rodovia Anhanguera, Km 174, Araras - São Paulo, CEP 13600-970. 
ção com bases orgânicas (ALTIERI, 1989; GLIESSMAN, 2001). Para a manutenção da integridade ambiental, a diversidade de espécies é condição fundamental nos ecossistemas (SANTOS et al., 2004).

Como a produção comercial do pinhão-manso inicia-se no terceiro ano de plantio (ARRUDA et al., 2004), é necessário realizar cultivos intercalares para viabilizar economicamente a cultura. Por consórcio de culturas entende-se o sistema de cultivo em que são plantadas duas ou mais espécies numa mesma área de terreno, de modo que uma das culturas conviva com a outra, proporcionando uma otimização da força de trabalho disponível, maiores safras e, consequentemente, maior lucratividade aos agricultores (MACHADO, 2008; APOLARI, 2009). Uma característica importante do consórcio é o maior aproveitamento da mesma área pelo agricultor, melhorando a eficiência do terreno, além da otimização da mão de obra, principalmente na agricultura familiar, do melhor aproveitamento de insumos e maior aproveitamento de máquinas e implementos, e ainda maior produção de biomassa quando comparado com o cultivo solteiro (MACHADO, 2008; APOLARI, 2009). Outra característica do plantio consorciado é o fomento da valoração ambiental, a paisagem de propriedades agrícolas apresenta uma vista muito mais diversificada, mais harmoniosa, quando comparada a um mar de monocultura em grandes extensões de terra (MARGARIDO, 1994). Os fatores de competição intraespecíficos e interespecíficos podem ser minimizados evitando o plantio adensado, respeitando a densidade populacional de cada espécie (GLIESSMAN, 2001).

A escolha do girassol como cultura intercalar deve-se ao fato de esta ser uma cultura anual, também produtora de biodiesel e, ao mesmo tempo, apresentar características alelopáticas, reduzindo o banco de sementes de plantas espontâneas no solo (SODRE FILHO et al., 2008). A área estimada de plantio de girassol em 2009/2010 é de 67,6 mil hectares (CONAB, 2009).

De acordo com a Lei 11.326, de 24 de julho de 2006, caracteriza-se como agricultura familiar aquela em que o empreendedor possui até quatro módulos fiscais (unidade de medida expressa em hectares, fixada para cada município, considerando o tipo de exploração predominante no município e a renda); utiliza, preferencialmente, a mão de obra familiar; tenha como renda predominante originária do estabelecimento rural e que administre sua propriedade (BRASIL, Lei 11.326, de 24 de julho de 2006). No Brasil, de acordo com o censo de 2006, existem 4.367.902 agricultores familiares, quase $85 \%$ das propriedades rurais, ocupando apenas $25 \%$ da área agricultável do país, são responsáveis por 38\% do valor de produção (INCRA, 2006).

O Brasil é a única grande economia com área agricultável suficiente para atender à demanda mundial por biocombustíveis, álcool e biodiesel, com competência e capacidade técnica para produzir com eficiência, sem detrimento da produção de alimentos (FREITAS, 2008). 0 biodiesel é um combustível biodegradável, derivado de fontes renováveis, o qual pode ser obtido por diferentes processos, tais como craqueamento, esterificação ou transesterificação (GEHLING, 2007), pode ser obtido por uma grande variedade de matérias primas, as quais incluem a maioria dos óleos vegetais, como óleo de mamona (Ricinus communis), soja (Glycine max), algodão (Gossypium hirsutum), dendê (Elacis guineensis), amendoim (Arachis hypogaea), colza (Brasica napus), babaçu (Orbygnya phalerata), girassol (Helianthus annuus), pinhão-manso (Jatropha curcas), entre outros, além de gorduras de origem animal (sebo) e óleos de descarte, usados em frituras (MOURAD, 2006).

0 pinhão-manso pertence à família Euphorbiaceae. Trata-se de um arbusto de grande porte, com altura variando entre três e cinco metros (CÁCERES et al., 2007), são plantas perenes, caducifólias e com boa tolerância à seca (HENNING apud SATURNINO et al., 2005). Possuem floração monóica, sendo as flores masculinas em maior número, sem pedúnculos, ocorrendo nas extremidades das ramificações, já as flores femininas ocorrem nas ramificações. Os frutos são capsulares, ovóides, com diâmetro de 1,5 a 3,0 centímetros, são triloculares com uma semente em cada cavidade. As sementes medem de 1,5 a 2 centímetros de comprimento e 1,0 a 1,3 centímetros de largura, com alto teor de óleo. Os teores de óleo podem chegar de 50 a 52\% quando extraído com solventes 
e 32 a 35\% quando extraído por pressão (PINHÃO MANSO, 2009). Essas variações também são influenciadas, dependendo da variedade (CORTESÃO apud VERDANA, 2006). Outra importante característica é o longo período de safra, de janeiro a julho, feita manualmente, favorecendo a fixação dos agricultores no campo (ARRUDA, et al., 2004).

Muitas dúvidas existem sobre a melhor forma de se plantar pinhão-manso, por ser uma cultura comercialmente nova, existem ainda inúmeras lacunas a serem estudadas na área de pesquisa, tais como as práticas culturais, as peculiaridades das diversas regiões produtoras, a grande variedade genética, indefinição do espaçamento ideal (VERDANA, 2006).

O girassol é uma cultura rústica, cultivada em diversas condições edafoclimáticas, e também excelente produtora de óleo vegetal comestível, muito usado no mundo (IAC, 2005). O teor de óleo na semente de girassol está na faixa de 40 a 48\%, com um rendimento de óleo por hectare de 0,5 a 1,9 toneladas (SLUSZZ; MACHADO, 2006).

A cultura do girassol é caracterizada por uma ação alelopática, que é uma interação entre dois organismos, onde um componente é afetado e o outro permanece estável (ALMEIDA, 1991). No caso do girassol, a alelopatia é dada pela ação de redução da atividade da glutationa redutase (GR) em sementes e radicelas de plantas espontâneas, inibindo as enzimas oxidativas, deixando as plantas vulneráveis aos danos oxidativos (WEIR; PARK; VIVANCO apud ALMEIDA et al., 2008). Além disso, o óleo de girassol apresenta alta qualidade nutricional e organoléptica, a possibilidade de uso como biodiesel, e como subproduto a torta, usada na ração animal (UNGARO, 2000). As outras partes do vegetal podem ainda ser utilizadas na fabricação de material acústico, silagem e no fomento à produção de mel (MOURAD, 2006). Também é muito utilizada para rotação de culturas e para o incremento da produção das culturas subsequentes. (SODRE FILHO et al., 2008).

As diferentes disposições das linhas de cultivo em relação ao movimento relativo do sol resultam em maior ou menor intercepção da irradiação solar pelas plantas, interferindo na taxa de produção de matéria seca. A taxa de produção de matéria seca do dossel de uma cultura depende essencialmente da quantidade de energia luminosa absorvida por seus componentes e de sua eficiência fotossintética (RODRIGUES; LEITE, 1999).

Em plantios com orientação norte-sul ocorre um aumento da penetração de luz, resultando em distribuição mais uniforme da produção em ambos os lados da planta (RASEIRA, 1992). Estudos sobre a produção das plantas cujos lados estejam voltados para o poente ou nascente indicam que as partes das plantas que permanecem sombreadas durante a maior parte do dia apresentam as menores produções (CRISÓSTOMO et al., 1992).

Em face destas informações sobre as culturas do pinhão-manso e do girassol, este trabalho visa avaliar a viabilidade técnica, econômica e as interações entre as espécies consorciadas.

\section{Material e métodos}

O experimento foi realizado em Araras, São Paulo, nas dependências do Centro de Ciências Agrárias (CCA) da Universidade Federal de São Carlos (UFSCar), latitude 22¹9'05.51" S, longitude 47022'42.39" W e altitude média de 691 metros. A temperatura média anual é de $21,4{ }^{\circ} \mathrm{C}$ e a precipitação anual de 1.428 milímetros, o clima da região é do tipo Cwa, mesotérmico, com verões quentes e úmidos e invernos secos (CCA, 2009). A área possui declive de $2 \%$ no sentido oeste/leste, as linhas de plantio seguiram orientação norte-sul, possibilitando o acompanhamento do pinhão-manso exposto ao sol matutino, ao sol vespertino ou a pleno sol. 0 solo predominante no local é classificado como Latossolo Vermelho-Escuro (MANIERO, 1980), a área útil do experimento compreendeu 0,1792 hectares. 0 delineamento estatístico utilizado foi o de parcelas subdivididas, contando com 4 tratamentos e 4 repetições, totalizando 16 parcelas. Cada parcela foi constituída de 
uma linha central de pinhão-manso, com sete plantas, com espaçamento entre plantas de 2 metros, com 14 metros de comprimento por 8 metros de largura, totalizando uma área útil para cada parcela de $112 \mathrm{~m}^{2}$. 0 consórcio foi realizado de acordo com os seguintes tratamentos (figura 1):

a) T1: plantio de girassol, 4 linhas de plantio a leste e 4 linhas de plantio a oeste da linha de pinhão-manso;

b) T2: plantio de 4 linhas de girassol a oeste da linha de plantio de pinhão-manso;

c) T3: plantio de 4 linhas de girassol a leste da linha de plantio de pinhão-manso;

d) T4: sem cultura intercalar, apenas a linha de pinhão-manso.

Figura 1. Croqui do experimento com as parcelas.

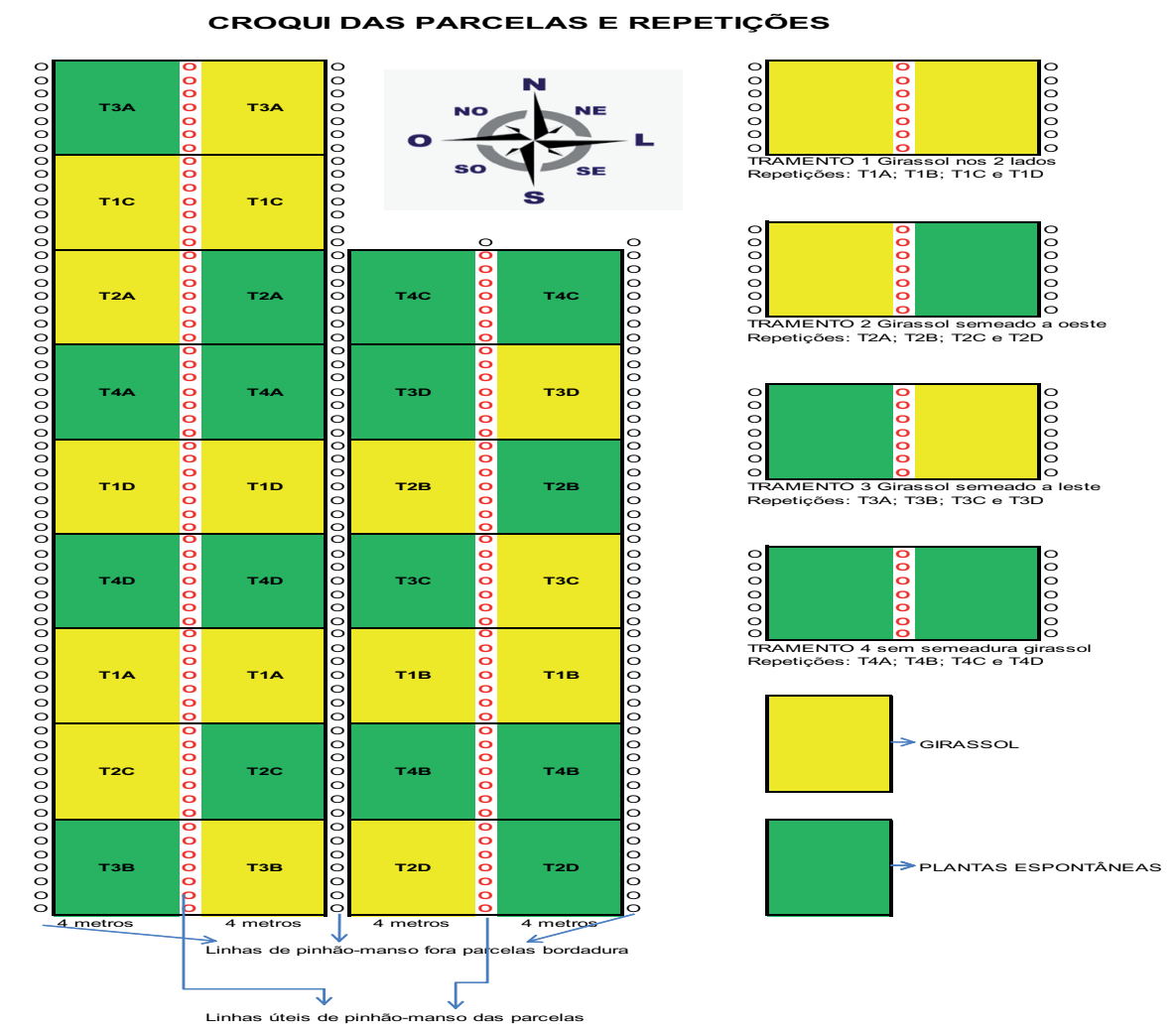

Fonte: Elaboração própria

No preparo da área foram adotados os seguintes procedimentos:

a) amostragens do solo nas profundidades de 0 a $20 \mathrm{~cm}$ e de 20 a $40 \mathrm{~cm}$ para caracterização da fertilidade (Tabela 1);

b) dispensa da correção de acidez do solo com base nos resultados das análises (Tabela 1);

c) duas gradagens para a limpeza e incorporação das plantas infestantes no início de março de 2008;

d) a abertura dos sulcos de plantio das mudas de pinhão-manso, com espaçamento de quatro metros entre os sulcos. 
Tabela 1. Amostragem de solo inicial, antes do plantio do pinhão-manso.

\begin{tabular}{|c|c|c|c|}
\hline & & \multicolumn{2}{|c|}{ Profundidade } \\
\hline & & 0 a $20 \mathrm{~cm}$ & 20 a $40 \mathrm{~cm}$ \\
\hline P Resina & $\mathrm{Mg} / \mathrm{dm} 3$ & 4 & 2 \\
\hline MO & $\mathrm{g} / \mathrm{dm}^{3}$ & 22 & 18 \\
\hline $\mathrm{pH}$ & $\mathrm{CaCl}_{2}$ & 4,7 & 4,8 \\
\hline K & & 1,2 & 0,7 \\
\hline $\mathrm{Ca}$ & & 19 & 17 \\
\hline $\mathrm{Mg}$ & & 9 & 7 \\
\hline $\mathrm{H}+\mathrm{Al}$ & $\mathrm{Mmol}_{\mathrm{c}} / \mathrm{dm}^{3}$ & 28 & 26 \\
\hline $\mathrm{Al}$ & & 2,3 & 2,2 \\
\hline SB & & 29,2 & 24,7 \\
\hline CTC & & 57,2 & 50,7 \\
\hline V & $\%$ & 51 & 49 \\
\hline$S$ & & 11 & 7 \\
\hline B & & 0,34 & 0,28 \\
\hline $\mathrm{Cu}$ & & 2,2 & 1,6 \\
\hline $\mathrm{Fe}$ & $\mathrm{Mg} / \mathrm{dm}^{3}$ & 24 & 13 \\
\hline $\mathrm{Mn}$ & & 2,9 & 10,0 \\
\hline $\mathrm{Zn}$ & & 2,9 & 0,3 \\
\hline
\end{tabular}

Fonte: Elaboração própria.

O plantio do pinhão-manso foi realizado em 20 de maio de 2008. Em outubro foi realizada nova amostragem do solo para determinação da fertilidade, antes da semeadura do girassol. Para o preparo do terreno, foi feita nova gradagem nas entrelinhas da cultura do pinhão-manso. Não foi realizada nenhuma correção do solo, já que o índice do $\mathrm{pH}$ em $\mathrm{CaCl}_{2}$ estava com o valor 5,0 (UNGARO, 2000). Também optou-se pela não adubação de plantio, visto que a área apresentava bons níveis de fertilidade (Tabela 2).

Optou-se pela escolha do girassol da variedade IAC-larama, devido ao seu ciclo curto, pequeno porte das plantas, maturação uniforme e um rendimento médio de grãos de $2.000 \mathrm{~kg} / \mathrm{ha}^{-1}$, acima da produtividade média brasileira, com 1,5 toneladas por hectare (CONAB, 2009). Apesar da sua quantidade média de óleo (40\%) se aproximar da de outras variedades de girassol, devido ao ciclo curto, a variedade IAC-larama destaca-se por produzir a mesma quantidade de óleo em menor tempo em relação às demais variedades. A semeadura do girassol foi realizada em 11 de novembro de 2008, utilizou-se uma plantadeira de quatro linhas, com espaçamento entre as linhas de 0,50 m. A plantadeira foi regulada para garantir uma densidade de plantio de 50.000 sementes por hectare, a uma profundidade de três centímetros (UNGARO, 2000). 
Tabela 2. Resultados da análise química de amostragem de solo, pré-plantio do girassol.

\begin{tabular}{ccc}
\hline & & $\begin{array}{c}\text { Profundidade (0 a 20 cm) } \\
\text { SOLIC (Pinhão) }\end{array}$ \\
\hline P Resina & $\mathrm{Mg} / \mathrm{dm}^{3}$ & 9 \\
$\mathrm{MO}$ & $\mathrm{g} / \mathrm{dm}^{3}$ & 25 \\
$\mathrm{pH}$ & $\mathrm{CaCl}_{2}$ & 5,0 \\
$\mathrm{~K}$ & & 1,3 \\
$\mathrm{Ca}$ & & 24 \\
$\mathrm{Mg}$ & & 13 \\
$\mathrm{H}+\mathrm{Al}$ & $\mathrm{Mmol}_{\mathrm{c}} / \mathrm{dm}^{3}$ & 13 \\
$\mathrm{Al}$ & & 1,4 \\
$\mathrm{SB}$ & & 38,3 \\
$\mathrm{CTC}$ & & 51,3 \\
$\mathrm{~V}$ & $\%$ & 75 \\
$\mathrm{~S}$ & & 4 \\
$\mathrm{~B}$ & & 0,22 \\
$\mathrm{Cu}$ & $\mathrm{Mg} / \mathrm{dm}^{3}$ & 1,3 \\
$\mathrm{Fe}$ & & 14 \\
$\mathrm{Mn}$ & & 12,0 \\
$\mathrm{Zn}$ & 0,6 \\
\hline
\end{tabular}

Fonte: Elaboração própria.

Durante a condução do experimento, para o girassol foram realizadas duas adubações de cobertura com ácido bórico, via foliar, aos 37 e 51 dias da semeadura, na dosagem equivalente a 2,5 quilos por hectare, por pulverização, de acordo com a recomendação de Ungaro (2000). No início de fevereiro foram colocados protetores de panos nas flores a fim de evitar o ataque de pássaros (Figura 2).

Figura 2. Pano protetor para evitar ataque de pássaros, observe ponto maturação.

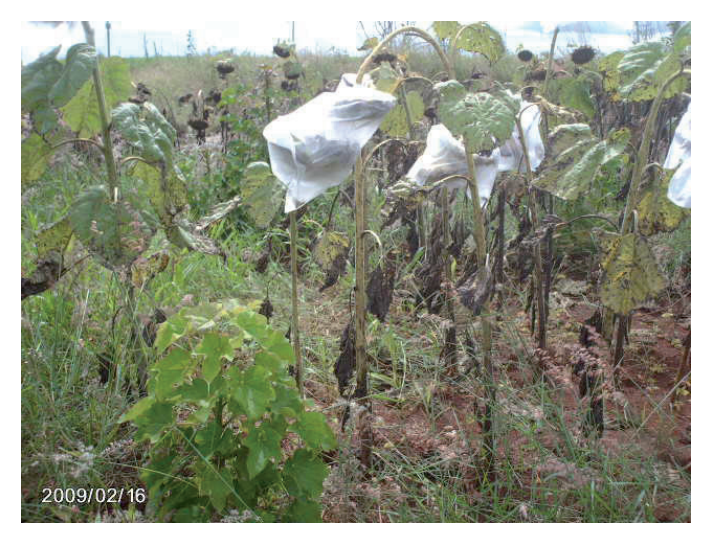

Fonte: Elaboração própria.

Para determinar a ação alelopática do girassol no controle das espécies infestantes e também possíveis interferências no desenvolvimento do pinhão-manso, foram determinadas as seguintes metodologias: Medições mensais de todas as plantas de pinhão-manso do experimento em relação à altura e diâmetro do colo (GUIMARÃES, 2008), num total de seis medições. No final da coleta de dados, para a análise estatística, foi determinado o delta crescimento individual de todas as plantas de pinhão-manso. Foi realizado o registro fotográfico mensal. 
A determinação da influência do plantio intercalar do girassol sobre o desenvolvimento das plantas espontâneas foi realizada em 02 de março, no final do ciclo da cultura do girassol, utilizando como gabarito um aro de ferro, com 40 centímetros de diâmetro $\left(0,126 \mathrm{~m}^{2}\right)$. 0 gabarito de ferro era jogado ao acaso, em todas as parcelas, tanto nas áreas com girassol, como nas áreas sem plantio intercalar, em seguida foram contadas e identificadas as espécies de plantas espontâneas, Foi feito um registro fotográfico individual de todas as amostragens.

a) Com o levantamento fotográfico da cobertura vegetal foi possível, de maneira rápida e eficiente, obter dados confiáveis, com técnicas de digitalização de imagens, utilizando o software SisCob 1.0, desenvolvido para a análise da cobertura do solo, uma versão para Windows desenvolvido pelo Cnpdia Embrapa (JOSÉ et. al, 2009). As imagens foram divididas em quatro grupos, sendo: Imagens referentes às subparcelas onde foi cultivado girassol intercalar, à oeste da linha de plantio de pinhão-manso, denominada de T1 Go;

b) Imagens referentes às subparcelas onde foi cultivado girassol intercalar à leste da linha de plantio de pinhão-manso, denominada $\mathrm{T} 2 \mathrm{Ge}$;

c) Imagens referentes às subparcelas onde não houve plantio intercalar à leste da linha de plantio de pinhão-manso, denominada de T3 Me;

d) Imagens referentes às subparcelas onde não houve plantio intercalar à oeste da linha de plantio de pinhão-manso, denominada de T4 Mo.

Para uniformidade de escala, as imagens foram recortadas no tamanho correspondente ao diâmetro do gabarito de aro de ferro e posteriormente digitalizadas e processadas.

Para determinação da produtividade do girassol, a área foi colhida manualmente, com identificação das subparcelas; após a secagem à sombra foi feito o beneficiamento do girassol em batedor de cereais. Cada parcela foi processada individualmente e posteriormente pesada para a determinação da produtividade por área útil.

\section{Resultados e discussão}

\subsection{Levantamentos da alelopatia do girassol}

O levantamento da cobertura do solo, feito aleatoriamente nas entrelinhas de cultivo do pinhão manso, cultivada ou não com girassol, cuja imagem foi digitalizada e processada pelo programa SisCob, demonstram o efeito alelopático do cultivo de girassol nas plantas espontâneas. Como exemplos, imagens de uma área cultivada com girassol na entrelinha do pinhão manso, com baixa incidência de plantas espontâneas, e imagens da área sem o cultivo do girassol na entrelinha, com alto índice de cobertura do solo e as respectivas imagens digitalizadas (Figuras 3, 4, 5 e 6). 
Figura 3. Imagem da área com girassol

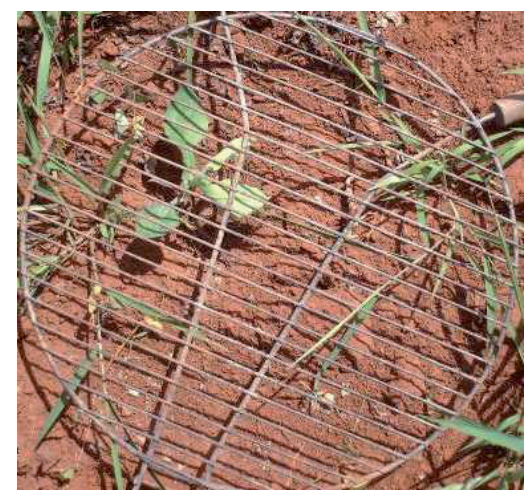

Figura 5. Imagem da área sem girassol

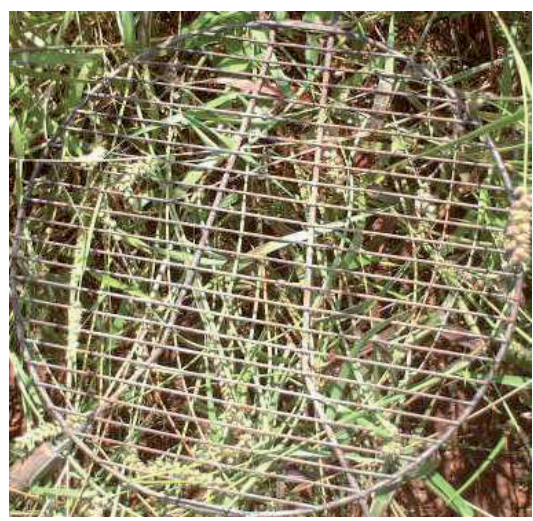

Figura 4. Imagem processada - área com girassol

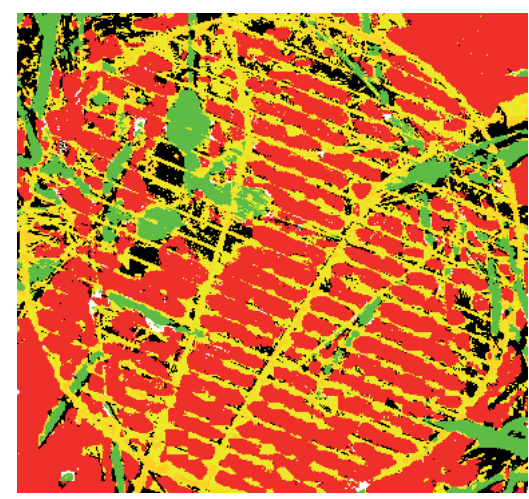

Figura 6. Imagem processada - área sem girassol

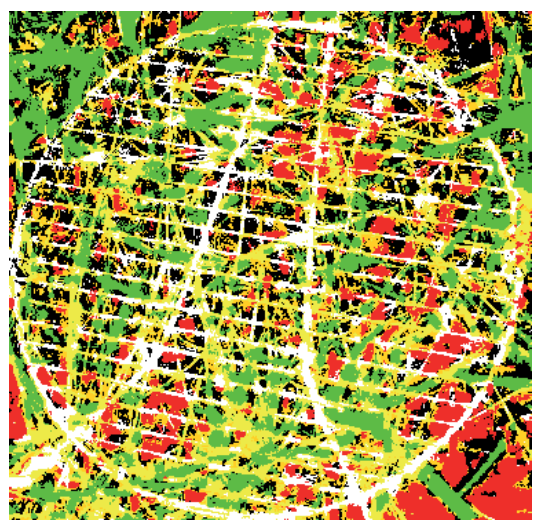

Fonte: Elaboração própria

A partir dos resultados da digitalização das imagens, utilizando o software SisCob 1.0, pôde-se determinar a influência do plantio intercalar do girassol sobre o desenvolvimento das plantas espontâneas e consequentemente, na porcentagem de cobertura do solo.

Os resultados obtidos da porcentagem de cobertura do solo foram classificados de acordo com a orientação no campo, posicionamento leste e oeste, em relação à linha de plantio do pinhão-manso e em relação à área de cultivo intercalar com plantio de girassol ou área de repouso (Tabela 3).

Os resultados do levantamento da cobertura do solo para a determinação da influência do plantio intercalar do girassol sobre o desenvolvimento das plantas espontâneas evidenciam que houve uma influência na cobertura do solo, resultado da soma da área foliar das plantas espontâneas, ocorrência de inflorescência e acúmulo de palhas e serrapilheira. 
Tabela 3. Porcentagens de cobertura verde do solo nas subparcelas, de acordo com o posicionamento leste e oeste, conforme o tipo de cultivo da área intercalar, girassol ou área de descanso.

\begin{tabular}{cccccccc}
\hline $\begin{array}{c}\text { Em área de cultivo in- } \\
\text { tercalar com girassol } \\
\text { à oeste da linha de } \\
\text { pinhão-manso }\end{array}$ & $\begin{array}{c}\text { Em área de cultivo } \\
\text { intercalar com giras- } \\
\text { sol à leste da linha de } \\
\text { pinhão-manso }\end{array}$ & $\begin{array}{c}\text { Em área interca- } \\
\text { lar de descanso à } \\
\text { leste da linha de } \\
\text { pinhão-manso }\end{array}$ & $\begin{array}{c}\text { Em área intercalar de } \\
\text { descanso à oeste da } \\
\text { linha de pinhão manso }\end{array}$ \\
\hline T1A oeste & 20,82 & T1A leste & 13,48 & T2A leste & 38,11 & T3A oeste & 33,29 \\
T1B oeste & 14,01 & T1B leste & 31,93 & T2B leste & 31,13 & T3B oeste & 63,13 \\
T1C oeste & 8,04 & T1C leste & 31,86 & T2C leste & 53,88 & T3C oeste & 62,18 \\
T1D oeste & 15,23 & T1D leste & 42,33 & T2C leste & 47,03 & T3D oeste & 83,63 \\
T2A oeste & 12,62 & T3A leste & 8,49 & T4A leste & 44,39 & T4A oeste & 43,8 \\
T2B oeste & 9,83 & T3B leste & 24,44 & T4B leste & 58,52 & T4B oeste & 80,85 \\
T2C oeste & 14,52 & T3C leste & 18,34 & T4C leste & 70,36 & T4C oeste & 54,85 \\
T2D oeste & 13,50 & T3D leste & 25,18 & T4D leste & 48,06 & T4D oeste & 91,85 \\
\hline
\end{tabular}

Fonte: Elaboração própria.

A cobertura vegetal foi menor nas áreas de cultivo do girassol, em comparação com as áreas sem o girassol, como ilustrado na Tabela 4.

Tabela 4. Análise de variância estatística na cobertura vegetal do solo, nas subparcelas, de acordo com a orientação leste ou oeste e de acordo com o tipo de cultivo intercalar, teste Tukey a $5 \%$ de probabilidade.

\begin{tabular}{cc}
\hline Analise de variância & Cobertura do solo \\
\hline Grau de Liberdade GL resíduo & 28 \\
F tratamentos & $24,33^{* *}$ \\
Média geral & 37,80 \\
Desvio-padrão & 13,18 \\
Diferença mínima significativa DMS (5\%) & 17,99 \\
Coeficiente de variação CV (\%) & 34,86 \\
\hline Teste de Tukey a 5\% & \\
\hline T1 Go & $13,57 \mathrm{~b}$ \\
T2 Ge & $24,51 \mathrm{~b}$ \\
T3 Me & $48,94 \mathrm{a}$ \\
T4 Mo & $64,20 \mathrm{a}$ \\
\hline
\end{tabular}

T1 Go - Grupo de subparcelas com girassol, à oeste da linha do pinhão manso.

T2 Ge - Grupo de subparcelas com girassol, à leste da linha do pinhão-manso.

T3 Me - Grupo de subparcelas, em repouso, à leste da linha de pinhão-manso.

T4 Mo - Grupo de subparcelas, em repouso, à oeste da linha de pinhão-manso.

Fonte: Elaboração própria. 
No período de observação do experimento, foram identificadas dezoito espécies de plantas infestantes na área experimental (Tabela 5).

Tabela 5. Diversidade da infestação de plantas espontâneas nas parcelas, com ou sem plantio de girassol.

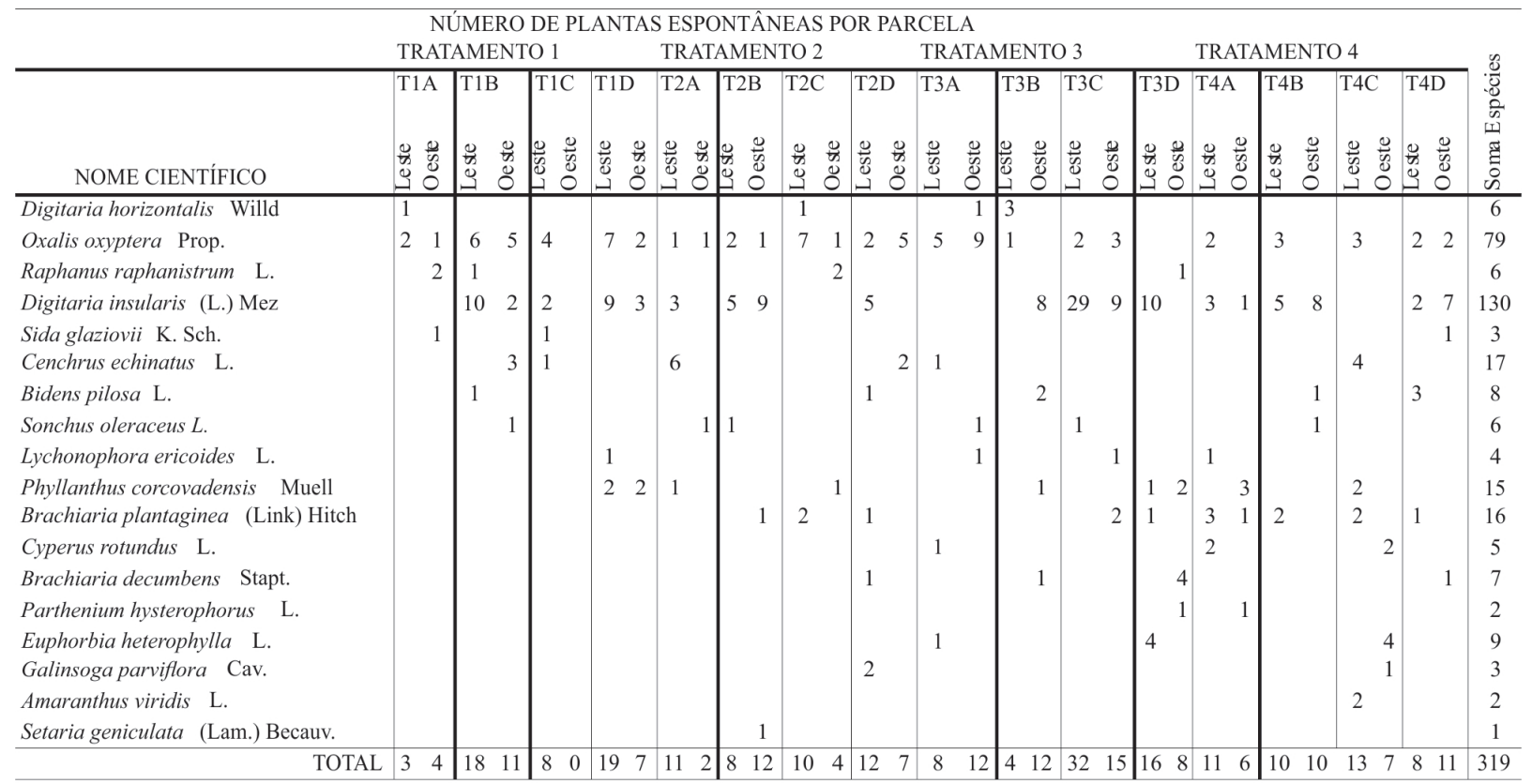

Fonte: Elaboração própria.

Não houve diferença estatística entre os tratamentos na diversidade de espécies, conforme tabela 6.

Tabela 6. Análise estatística de diversidade de plantas espontâneas.

\section{Analise de variância}

Grau de Liberdade GL resíduo

$\mathrm{F}$ tratamentos

Média geral

Desvio-padrão

Diferença mínima significativa DMS (5\%)

Coeficiente de variação CV (\%)

\section{Cobertura do solo}

24

1,13

10,06

6,24

14,63

62,06

\begin{tabular}{cc}
\hline Teste de Tukey a 5\% & \\
\hline T1 leste & $12,00 a$ \\
T1 oeste & $5,50 a$ \\
T2 leste & $10,25 a$ \\
T2 oeste & $6,25 a$ \\
T3 leste & $15,75 a$ \\
T3 oeste & $11,75 a$ \\
T4 leste & $10,50 a$ \\
T4 oeste & $8,50 a$ \\
\hline
\end{tabular}

T1 Go - Grupo de subparcelas com girassol, à oeste da linha do pinhão manso. 
T2 Ge - Grupo de subparcelas com girassol, à leste da linha do pinhão-manso.

T3 Me - Grupo de subparcelas, em repouso, à leste da linha de pinhão-manso.

T4 Mo - Grupo de subparcelas, em repouso, à oeste da linha de pinhão-manso.

Fonte: Elaboração própria.

\subsection{Produtividade do girassol}

A produtividade do girassol, nas quatro repetições, expressa em $\mathrm{kg} / \mathrm{ha}^{-1}$ na tabela 7 , indica que não houve diferença estatística ao nível de 5\% de probabilidade entre os tratamentos. A produtividade média entre todos os tratamentos foi de $1477,45 \mathrm{~kg} / \mathrm{ha}^{1}$, próxima à média nacional que é de 1,5 ton./ha-1.

Tabela 7. Resultados da produção de girassol, correspondente a $\mathrm{kg} / \mathrm{ha}^{-1}$, obtidos em sistema de consórcio com pinhão-manso, de acordo com cada tratamento, média de quatro repetições.

\section{Tratamentos}

Produção $\left(\mathrm{kg} / . . \mathrm{ha}^{-1}\right)$

T 1 girassol plantado à leste da linha pinhão-manso $1.371,4 \mathrm{a}$

T 1 girassol plantado à oeste da linha pinhão-manso

$1.489,3$ a

T 2 girassol plantado à oeste da linha pinhão-manso

$1.635,7$ a

T 3 girassol plantado a leste da linha pinhão-manso $1.407,2$ a

CV\% 23,6

Médias seguidas de letras iguais, na coluna, não deferem entre si pelo teste de Tukey a $5 \%$ de probabilidade. Fonte: Elaboração própria.

\subsection{Crescimento do pinhão-manso}

As medições do desenvolvimento das plantas de pinhão-manso foram feitas mensalmente, do período de 12 de dezembro de 2008 a 7 de maio de 2009, totalizando seis amostragens. Foram medidos o diâmetro do colo da planta, em milímetros, e a altura total das plantas, em centímetros, na totalidade de plantas de cada parcela (sete plantas por parcela).

Quanto ao crescimento do pinhão manso, não foram encontradas diferenças estatisticamente significativas entre os tratamentos em nenhuma das seis épocas analisadas durante o ciclo da cultura intercalar do girassol de 120 dias. Esses resultados sugerem que não houve competição entre o girassol e o pinhão-manso. Entretanto, houve variação significativa entre o tamanho final das plantas de pinhão-manso, indicando uma grande diversidade entre as mudas marcadas no sentido vertical (Tabela 8).

Tabela 8. Delta crescimento médio, em centímetros, das plantas de pinhão-manso.

\begin{tabular}{cccccccc}
\hline Tratamento & $\mathbf{1 0 / 1 2 / 0 8}$ & $\mathbf{0 8 / 0 1 / 0 9}$ & $\mathbf{0 5 / 0 2 / 0 9}$ & $\mathbf{1 0 / 0 3 / 0 9}$ & $\mathbf{0 8 / 0 4 / 0 9}$ & $\mathbf{0 7 / 0 3 / 0 9}$ & Médias \\
\hline T1 & $44 \mathrm{aD}$ & $62 \mathrm{aC}$ & $78 \mathrm{aB}$ & $90 \mathrm{aAB}$ & $94 \mathrm{aA}$ & $96 \mathrm{aA}$ & $77 \mathrm{a}$ \\
T2 & $38 \mathrm{aC}$ & $50 \mathrm{aC}$ & $67 \mathrm{aB}$ & $77 \mathrm{aAB}$ & $79 \mathrm{aAB}$ & $82 \mathrm{aA}$ & $65 \mathrm{a}$ \\
T3 & $43 \mathrm{aC}$ & $55 \mathrm{aC}$ & $74 \mathrm{aB}$ & $85 \mathrm{aAB}$ & $88 \mathrm{aA}$ & $91 \mathrm{aA}$ & $72 \mathrm{a}$ \\
T4 & $40 \mathrm{aC}$ & $52 \mathrm{aC}$ & $69 \mathrm{aB}$ & $84 \mathrm{aA}$ & $86 \mathrm{aA}$ & $89 \mathrm{aA}$ & $70 \mathrm{a}$ \\
\hline Médias & $41 \mathrm{D}$ & $55 \mathrm{C}$ & $72 \mathrm{~B}$ & $84 \mathrm{~A}$ & $87 \mathrm{~A}$ & $89 \mathrm{~A}$ &
\end{tabular}

Médias seguidas de letras distintas, na coluna, diferem entre si pelo teste de Tukey a $5 \%$ de probabilidade.

N.B. Minúsculas na vertical, maiúsculas na horizontal (a, A: maior média etc.) Desvio padrão (a) 28,83 Desvio padrão (b) 7,53 - Coeficiente de variação \% (a) 41,94 Coeficiente de variação \% (b) 10,58.

Fonte: Elaboração própria. 
Quanto ao desenvolvimento e aumento do diâmetro do caule na região do colo das plantas, durante o período de levantamento também não houve diferenças estatísticas ao nível de $5 \%$ de significância entre os tratamentos (Tabela 9). Em relação ao diâmetro médio do colo e à altura média das plantas, médio em todos os tratamentos, inclusive para o pinhão-manso solteiro, é possível afirmar que não houve o estiolamento do pinhão-manso à procura de luminosidade.

Tabela 9. Delta crescimento médio, em centímetros, das plantas de pinhão-manso

\begin{tabular}{cccccccc}
\hline Trat. & $\mathbf{1 0 / 1 2 / 0 8}$ & $\mathbf{0 8 / 0 1 / 0 9}$ & $\mathbf{0 5 / 0 2 / 0 9}$ & $\mathbf{1 0 / 0 3 / 0 9}$ & $\mathbf{0 8 / 0 4 / 0 9}$ & $\mathbf{0 7 / 0 3 / 0 9}$ & Médias \\
\hline T1 & $22 \mathrm{aC}$ & $28 \mathrm{aC}$ & $36 \mathrm{aB}$ & $41 \mathrm{aAB}$ & $45 \mathrm{aA}$ & $48 \mathrm{aA}$ & $37 \mathrm{a}$ \\
$\mathrm{T} 2$ & $19 \mathrm{aD}$ & $24 \mathrm{aCD}$ & $31 \mathrm{aBC}$ & $37 \mathrm{aAB}$ & $41 \mathrm{aA}$ & $44 \mathrm{aA}$ & $33 \mathrm{a}$ \\
$\mathrm{T} 3$ & $20 \mathrm{aD}$ & $26 \mathrm{aD}$ & $33 \mathrm{aC}$ & $38 \mathrm{aBC}$ & $42 \mathrm{aB}$ & $50 \mathrm{aA}$ & $35 \mathrm{a}$ \\
T4 & $19 \mathrm{aD}$ & $25 \mathrm{aD}$ & $33 \mathrm{aC}$ & $39 \mathrm{aBC}$ & $43 \mathrm{aAB}$ & $46 \mathrm{aA}$ & $34 \mathrm{a}$ \\
\hline Médias & $20 \mathrm{~F}$ & $26 \mathrm{E}$ & $33 \mathrm{D}$ & $39 \mathrm{C}$ & $43 \mathrm{~B}$ & $47 \mathrm{~A}$ & \\
\hline
\end{tabular}

Médias seguidas de letras distintas, na coluna, diferem entre si pelo teste de Tukey a $5 \%$ de probabilidade. N.B. Minúsculas na vertical, maiúsculas na horizontal (a, A: maior média etc.) Desvio padrão (a) 11,47 Desvio padrão (b) 2,52 - Coeficiente de variação \% (a) 33,60 Coeficiente de variação \% (b) 7,38.

Fonte: Elaboração própria.

\section{Conclusões}

O consórcio de pinhão-manso com o girassol, nas condições do experimento, mostrou-se perfeitamente viável, não houve influência alelopática do girassol no desenvolvimento inicial das plantas de pinhão-manso.

Não foi observada influência do pinhão-manso na produtividade do girassol, a média da produção nos tratamentos foi equivalente à média nacional de produção de girassol.

Ocorreu um efeito supressivo no desenvolvimento das plantas espontâneas nas áreas onde foi feito o plantio intercalar do girassol nas entrelinhas do pinhão-manso, reduzindo significativamente a cobertura do solo.

Não houve influência alelopática do girassol na diversidade e seleção das plantas espontâneas.

\section{Viability and interactions of component crops of jatropha and sunflower}

\section{Abstract}

With the recent advent of biodiesel in Brazil, there has been a significant increase in the number of research on the potential of utilizing oleaginous as raw material, especially in jatropha (Jatropha curcas L.), due to its superior oil technical characteristics, as well as the plant's hardiness and productivity. However, since the production of jatropha only becomes economically viable from the third year, there is a need to consider planting in intercropping manner. The aim of this study was to 
evaluate the interaction and the technical and economical feasibility of intercropping of jatropha and sunflower (Helianthus annuus L.), which is also an excellent source of oil for biodiesel production. The project was implemented at UFSCar / CCA in Araras, São Paulo. The jatropha seedlings were planted in May 1998, spaced 2 meters between plants and 4 meters between rows. The sowing of sunflower variety larama was done in November 2008, with four rows spaced at fifty centimeters, with an estimated 50,000 plants per hectare. We evaluated the sunflower plant yield, the development of jatropha and the possible allelopathic interactions between cultures. Allelopathic effects between sunflower and weeds were also investigated. We adopted the split-plot design with four replications and four combinations of consortia, whereas $\mathrm{T} 1$ : growing sunflowers on both sides of the jatropha planting, T2: growing sunflowers west of the jatropha planting with the east side being reserved for the germination of weeds, T3: growing sunflowers to the east line of jatropha with the west side being reserved for the germination of weeds; T4: both sides of the line of Jatropha curcas were reserved for the germination of weeds. It was concluded that there was no influence on the development of jatropha plantations in intercropped with sunflower and sunflower production was not affected by jatropha. There was also a suppression of spontaneous plants in areas with sunflower. The alternative of this consortium demonstrates a good choice for the national biodiesel program.

Keywords: Ecology. Allelopathy. Family farming.

\section{Referências bibliográficas}

ALMEIDA, F. S., Efeitos alelopáticos de resíduos vegetais. Revista Agropecuária Brasileira, Brasília, n. 26, p. 221-236, fev. 1991.

ALMEIDA, G. D. et al. Estresse oxidativo em células vegetais mediante aleloquímicos. Revista da Faculdade Nacional de Agronomia de Medellín, Medelin, p. 4237-4247, mai. 2008.

ALTIERI, M. A. Agroecologia: as bases científicas da agricultura alternativa. Rio de Janeiro: PTAFASE, 1989. 237 p.

APOLARI, J. P. Sistema de produção orgânico de milho (Zea mays L.), feijão (Phaseolus vulgaris L.) e mandioca (Manihot esculenta CRANTZ), consorciado com soqueira de cana-de-açúcar (Saccharum sppp). 2009. Dissertação (Mestrado). Universidade Federal de São Carlos, Centro de Ciências Agrárias, Araras.

ARRUDA, F. P. et al. Cultivo de pinhão-manso (Jatropha curcas L.) como alternativa para o semiárido nordestino. Revista Brasileira de Oleaginosas e Fibrosas, Campina Grande, v. 8, n. 1, p. 789-799, jan. 2004.

BRASIL, Lei 11.326, de 24 de julho de 2006.

CÁCERES, D. R.; PORTAS, A. A.; ABRAMIDES, J. E. Pinhão-manso. 2007. Disponível em: <http://www.infobibos.com/Artigos/2007_3/>. Acesso em: 09 out. 2008.

CENTRO DE CIÊNCIAS AGRÁRIAS - CCA. Dados Climatológicos: Araras. Disponível em: <http:// www.cca.ufscar.br/servicos/dados-climatologicos/>. Acesso em: 09 set. 2009. 
COMPANHIA NACIONAL DE ABASTECIMENTO - CONAB. Acompanhamento da safra brasileira de grãos 2009/2010: estimativa de safra. Disponível em: <http://www.conab.gov.br > . Acesso em: 18 dez. 2009.

CRISÓSTOMO, J. R.; ALMEIDA, J. I. L.; GADELHA, J. W. R.; FELIPE, E. M. Orientação para o plantio de cajueiro em relação aos pontos cardeais. Comunicado Técnico MARA/EMBRAPA/ CNPCa, Fortaleza- CE, n. 03, p. 1-2, out. 1992.

FREITAS, C. Brasil é o grande favorito na corrida mundial dos bicombustíveis. Agrianual 2008. São Paulo: FNP Consultoria, p. 32 e 33, 2008.

GEHLING, R.. Alternativas à matriz energética brasileira: o caso do biodiesel. 2007. 80p. Monografia (Curso de Ciências Econômicas), Universidade Federal de Santa Catarina, Florianópolis.

GLIIESSMAN, S. R. Agroecologia: processos ecológicos em agricultura sustentável. 2 ed. Porto Alegre: UFRRGS, 2001.

GUIMARÃES, A. S., Crescimento inicial do pinhão manso (Jatropha curcas L 1753.) em função de fontes e quantidades de fertilizantes. 2008. 92p. Tese (Doutorado). Universidade Federal da Paraíba, Areia.

INSTITUTO NACIONAL DE COLONIZAÇÃO E REFORMA AGRÁRIA. Portal censo 2006. Disponível em: <http://www.incra.gov.br>. Acesso em: 21 nov. 2009.

INSTITUTO AGRONÔMICO DE CAMPINAS. Cultivares Girassol IAC-Iarama, 2005. Disponível em: <http://www.iac.sp.gov.br>. Acesso em: 5 de dez. 2009.

JOSÉ, J. V.; ALMEIDA, E. L. D.; PICOLI JUNIOR, G. J.; SOARES, D.; BORGES, T. F.; RAMARI, T. O. I.; CASTRO, R. M.; BERTONHA, A. Uso de imagem digital para determinação da taxa de transpiração do cafeeiro. In: VI EPCC - Encontro Internacional de Produção Científica Cesumar, 2009, Maringá-PR. Anais... Maringá-PR: Cesumar, 2009.

MACHADO, R. Sistema de produção orgânicos para a soca da cultura da cana-de-açúcar (Saccharum spp.) consorciado com milho (Zea mays), feijão (Phaseolus vulgaris) e mandioca (Manihot esculenta). 2008. Dissertação (Mestrado). Universidade Federal de São Carlos, Centro de Ciências Agrárias, Araras.

MANIERO, M. A. Aplicação do método de graus-dia em cana-de-açúcar (Saccharum spp). 1980. 76p. Dissertação (Mestrado). Escola Superior de Agricultura "Luiz de Queiroz", Universidade de São Paulo, Piracicaba.

MARGARIDO, L. A. C. Valoração ambiental de alguns aspectos funcionais de uma área natural de conservação - estudo de caso: estação ecológica de Jataí. 92p. Dissertação de Tese (Doutorado). Universidade Federal de São Carlos, São Carlos, 1994.

MOURAD, A. L. Principais culturas para obtenção de óleos vegetais combustíveis no Brasil. In: AGRENER: $6^{\circ}$ CONGRESSO INTERNACIONAL SOBRE GERAÇÃO DISTRIUÍDA E ENERGIA NO MEIO RURAL, 2006, Campinas. AGRENER GD, 2006. 
PINHÃO MANSO. Pinhão Manso: uma planta do futuro. Disponível em: <http://www. pinhaomanso.com.br>. Acesso em 19 out. 2009.

RASEIRA, A. Influência da poda mecânica de verão, orientação da linha e espaçamento de plantas no rendimento de pêssego. Revista Agropecuária Brasileira, Brasília, n. 27, p. 493-498, mar. 1992.

RODRIGUES, E. F.; LEITE, I. C. Crescimento de genótipos de sorgo plantados nos sentidos norte-sul e leste-oeste. Pesquisa Agropecuária Brasileira, Brasília, v.34, n.2, p.173-179, fev. 1999.

SANTOS, J. E. et al. (Orgs.). Faces da polissemia da paisagem: ecologia, planejamento e percepção. São Carlos: RIMA, 2004. v. 1, 407 p.

SATURNINO, H. M. et al. Cultura do pinhão-manso (Jatropha curcas L.). Informe Agropecuário, Belo Horizonte, v. 26, n. 229, p. 44-78, mai. 2005.

SLUSZZ, T.; MACHADO, J. A. D. Características das potenciais culturas matérias-primas do biodiesel e sua adoção pela agricultura familiar. In: AGRENER - $6^{\circ}$ CONGRESSO INTERNACIONAL SOBRE GERAÇÃO DISTRIUÍDA E ENERGIA NO MEIO RURAL, 2006, Campinas. AGRENER GD, 2006.

SODRÉ FILHO, J.; CARMONA, R.; CARDOSO, A. N.; CARVALHO, A. M. Culturas de sucessão ao milho na dinâmica populacional de plantas daninhas. Scientia Agraria, Curitiba, v.9, n.1, p.7-14, 2008.

UNGARO, M. R. G. Cultura do girassol. Boletim técnico 188. Instituto Agronômico de Campinas, Campinas, 2000. 36p.

VERDANA, J. C. S. 2006. "Tudo sobre Pinhão Manso - Jatropha curcas". Disponível em: < http:// www.pinhaomanso.com.br>. Acesso em: 21 nov. 2009.

\section{Histórico editorial}

Recebido: 08/11/2012

Avaliação e copidesque: 21/11/2012 a 18/06/2013 


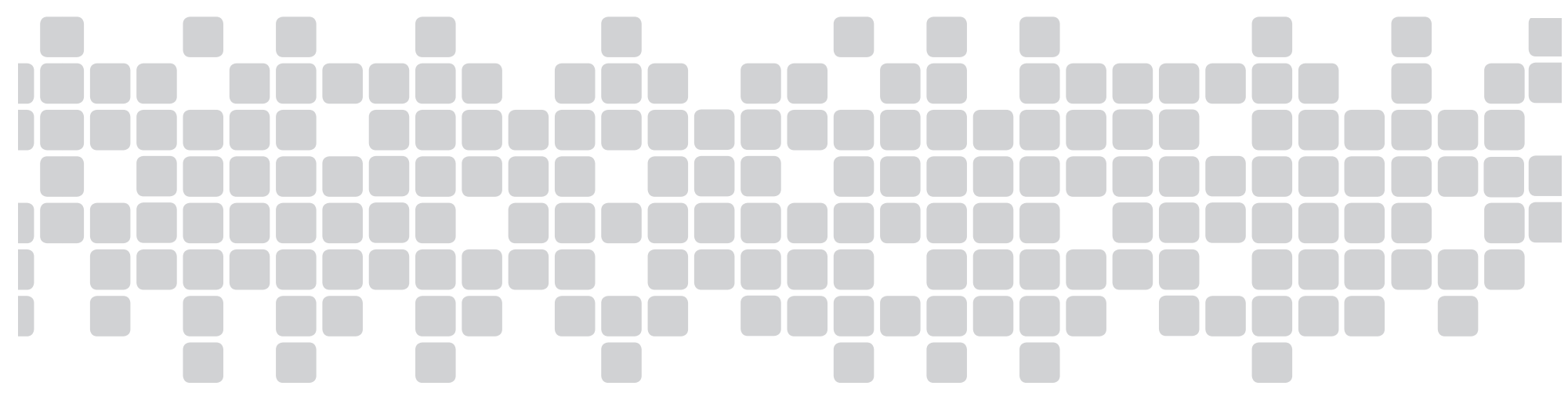

